\title{
El factor de crecimiento transformante $\beta$ como blanco terapéutico
}

Francisco Javier Gálvez-Gastélum, Biól, (1) A na Soledad Sandoval-Rodríguez, Q FB, ${ }^{(1)}$

Juan Armendár iz-Borunda, Dr en C..1)

\section{Gálvez-Gastélum FJ, Sandoval-Rodríguez AS,} Armendáriz-Borunda J.

El factor de crecimiento transformante $\beta$ como blanco terapéutico.

Salud Publica Mex 2004;46:341-350.

El texto completo en inglés de este artículo está disponible en: http://www.insp.mx/salud/index.html

\section{Resumen}

El factor de crecimiento transformante $\beta$ (TGF- $\beta$ ) es una familia de proteínas que incluye al TGF- $\beta$, activinas y a la proteína morfogénica de hueso (BMP, por sus siglas en inglés), cito cinas que son secretadas y se relacionan estructuralmente en diferentes especies de metazoarios. Los miembros de la familia del T G F- $\beta$ regulan diferentes funciones celulares como proliferación, apoptosis, diferenciación, migración, y tienen un papel clave en el desar rollo del organismo. El TGF- $\beta$ está implicado en varias patologías humanas, incluyendo desórdenes autoinmunes y vasculares, así como enfermedades fibróticas y cáncer. La activación del receptor delTGF- $\beta$ propicia su fosforilación en residuos de serina/treonina y dispara la fosforilación de proteínas efectoras intracelulares (smad), que una vez activas se translocan al núcleo para inducir la transcripción de genes blanco, y así regular procesos y funciones celulares. Se están desarrollando novedosas estrategias terapéuticas encaminadas a corregir las alteraciones presentes en patologías que involucran al TGF- $\beta$ como actor principal. El texto completo en inglés de este artículo está disponible en: http:// www.insp.mx/salud/index.html

Palabras clave: transducción de señal; factor beta transformador de crecimiento; smad; receptor

\author{
Gálvez-Gastélum FJ, Sandoval-Rodríguez AS, \\ Armendáriz-Borunda J. \\ Transforming growth factor- $\beta$ \\ as a therapeutic target. \\ Salud Publica Mex 2004;46:341-350. \\ The English version of this paper \\ is available at: http://www.insp.mx/salud/index.html
}

\section{A bstract}

Transforming growth factor- $\beta$ (TGF- $\beta$ ) family members include TGF- $\beta$, activins, and bone morphogenetic proteins (BMP). These proteins are structurally related cytokines secreted in diverse Metazoans. TGF- $\beta$ family members regulate cellular functions such as proliferation, apoptosis, differentiation, and migration, and play an important role in organism development. D eregulated TG F- $\beta$ family signaling participates in various human pathologies including autoimmune diseases, vascular disorders, fibrotic disease, and cancer. Ligand-induced activation ofT G F- $\beta$ family receptors with intrinsic serine/threonine kinase activity, triggers phosphorylation of the intracellular effectors of TGF- $\beta$ signaling, the Smads proteins. 0 nce these proteins are activated they translocate into the nucleus, where they induce transcription of tar get genes and regulate cellular processes and functions. Novel therapeutic strategies are currently being developed to correct alterations in pathologies that involve TGF- $\beta$ as the main mediator. The English version of this paper is available at: http://www.insp.mx/salud/index.html

Key words: signal transduction; transforming grouth factor beta; smad; receptor

(1) Instituto de Biología Molecular y Terapia Génica, Centro Universitario de Ciencias de la Salud, Universidad de Guadalajara, Jalisco, México.

Fecha de recibido: 17 de febrero de 2004 - Fecha de aprobado: 22 de junio de 2004 Solicitud de sobretiros: D r. Juan Armendáriz Borunda. A partado Postal 2-123, 44281 Guadalajara, Jalisco, México. Correo electrónico: armendbo@ cucs.udg.mx 


\section{Historia}

La historia del descubrimiento y el aislamiento original del factor de crecimiento (TGF- $\beta$ ) describe la actividad de esta molécula en términos simplistas. Durante los años 70 hubo grandes inquietudes por definir factores de crecimiento peptídico individuales que podían conferir un fenotipo transformado en células no malignas; dicha transformación era posible en células que crecían en cultivo de una manera independiente del anclaje. Lo más prominente fue la descripción en 1978 de un factor de crecimiento del sarcoma, el cual provenía de un extracto de células transformadas por virus, que causaba que los fibroblastos de riñón de rata normal (NRK, por sus siglas en inglés) crecieran en medio con agar. Cuando este extracto fue purificado, se encontró que la habilidad para causar el crecimiento era el resultado de dos péptidos nombrados posteriormente TGF- $\alpha$ y TGF- $\beta$; pero no fue sino hasta 1981 cuando Anita Roberts y colaboradores en su laboratorio de los Institutos Nacionales de Salud (NIH, por sus siglas en inglés) identificaron al TGF- $\beta$ como una molécula involucrada en un sinnúmero de procesos biológicos. Originalmente el TGF- $\beta 1$ fue el primero en purificarse de plaquetas y placenta humanas, y riñón de bovino, y ser caracterizado como un homodímero de 25 kDa. ${ }^{1}$

El TGF- $\beta$ es una superfamilia de proteínas integrada por más de 35 citocinas que incluye a las activinas, inhibinas, proteína morfogénica de hueso (BMP, por sus siglas en inglés), hormona anti-müleriana y al factor de crecimiento transformante $\beta$ propiamente dicho, que regulan una gran cantidad de actividades biológicas como proliferación, migración y apoptosis en diferentes tipos celulares, tanto en el estado adulto como durante el desarrollo embrionario. ${ }^{1}$

Todos estos factores de crecimiento comparten un grupo de residuos de cisteína altamente conservados que forman una estructura común, sostenida por enlaces disulfuro intramoleculares. ${ }^{2,3}$

Las activinas y las BMP juegan un papel importante durante el desarrollo embrionario; las activinas inducen el mesodermo dorsal en embriones de Xenopus laevis, y las BMP también desempeñan importantes funciones al inducir el mesodermo ventral en este mismo organismo. ${ }^{4}$

El TGF- $\beta$ es considerado como una citocina multifuncional (pleiotrópica) debido a los efectos que tiene sobre los diferentes tipos celulares. Es el inhibidor más potente de proliferación en células mieloides, mesenquimales, epiteliales, linfoides, endoteliales y en varios tipos de células malignas. Alternativamente, puede estimular la proliferación de fibroblastos normales en células no epiteliales y cierto tipo de células mesenquimales. Es un fuerte estimulador de la síntesis y depósito de proteínas de matriz extracelular por parte de fibroblastos, osteoblastos y células endoteliales; además, induce la expresión de integrinas y receptores que median las interacciones celulares con proteínas de matriz extracelular. Particularmente el TGF- $\beta 1$ también induce otros eventos intracelulares como la regulación de factores de crecimiento que intervienen en la diferenciación celular; induce cambios de expresión de los genes jun-B, c-fos y c-myc; induce recambio de IP3; evita la fosforilación de la proteína $\mathrm{Rb}$ (retinoblastoma), dependiente del contacto célula-célula e induce la activación de proteínas $\mathrm{G}^{5}$

\section{Estructura}

Existen cinco isoformas del TGF- $\beta$ en diferentes organismos, como se muestra en la figura 1. Adicionalmente, un heterodímero del TGF- $\beta$ (TGF- $\beta 1.2)$ se ha identificado en plaquetas porcinas. En mamíferos se han descrito tres formas del TGF- $\beta(-\beta 1,-\beta 2$ y $-\beta 3)$, las cuales residen en diferentes cromosomas (19q13, 1q41 y 14q24 en humanos, respectivamente), pero po-

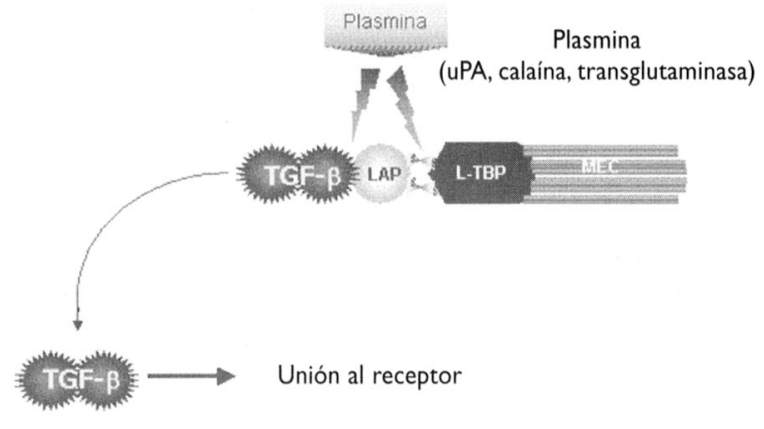

UPA: activador de plasminógeno tipo urocinasa MEC: matriz extracelular L-TBP: péptido asociado a TGF- $\beta$ latente LAP: péptido asociado a la latencia

Figura 1. Estructura y activación del TGF- $\beta$. Es sinTETIZADO COMO UNA MOLÉCULA INACTIVA, UNIDA A UNA SECUENCIA DE AMINOÁCIDOS, CONOCIDA COMO PÉPTIDO ASOCIADO A LA LATENCIA (LAP), QUE ESTÁ ANCLADA A LA MATRIZ EXTRACELULAR MEDIANTE UNA PROTEÍNA DENOMINADA PROTEÍNA DE UNIÓN AL TGF- $\beta$ LATENTE (LTBP, POR SUS SIGLAS EN INGLÉS), QUE TIENE QUE SER PROTEOLITICAMENTE SEPARADA PARA QUE ELTGF- $\beta$ PUEDA UNIRSE A SU RECEPTOR 
seen $80 \%$ de homología en secuencia de aminoácidos, mientras que las isoformas 4 y 5 se han identificado en aves y anfibios, respectivamente. ${ }^{5-7} \mathrm{El}$ TGF- $\beta$ es producido como un precursor dimérico de $25 \mathrm{kDa}$, secretado en forma latente (anclado a superficie celular o a la matriz extracelular), que posee 390 aminoácidos, en el cual la porción C-terminal de 112-114 aminoácidos posee nueve residuos de cisteína, y es la región activa después de que es cortada proteolíticamente en el aminoácido $278.5,6,8$

La activación del TGF- $\beta$ es dada por varios factores, incluyendo $\mathrm{pH}$ extremo, altas temperaturas, proteolisis limitada o desglucosilación del péptido asociado a la latencia (LAP, por sus siglas en inglés). ${ }^{9}$ También existe un mecanismo particular de activación, iniciado por la unión del complejo latente del TGF- $\beta 1$ a la glucoproteína de matriz extracelular llamada trombospondina 1 (TSP-1). ${ }^{10}$

Muchos tipos celulares expresan los TGF- $\beta 1$ y TGF- $\beta 2$ con $70 \%$ de homología en su secuencia de aminoácidos, mientras que el TGF- $\beta 3$ es sintetizado por células mesenquimales y posee $79 \%$ de homología con el TGF- $\beta 2$. Entre los mamíferos, la secuencia de aminoácidos del TGF- $\beta 1$ es altamente conservada (100\%), ya que es idéntica en humanos, cerdos, vacas y monos y difiere sólo en un aminoácido en ratones. La estructura tridimensional de la proteína del TGF$\beta 1$ comienza en el extremo $\mathrm{N}$-terminal con una cadena $\alpha$-hélice $(\alpha 1)$ seguida por una cadena $\beta$-plegada $(\beta 1)$ y una cadena $\beta$-plegada antiparalela irregular. En segundo término, sigue una segunda cadena $\alpha$-hélice $(\alpha 2)$ y un asa larga con numerosos contactos hidrofóbicos. Se continúa con una segunda cadena $\beta$-plegada $(\beta 2)$, otra asa larga y una tercera cadena $\alpha$-hélice $(\alpha 3)$, la cual termina con un giro $\beta$-tipo II y un asa larga. El extremo C-terminal de la molécula forma una estructura $\beta$-antiparalela extensa con un giro $\beta$ tipo II. Las cadenas $\beta 3$, $\beta 4, \beta 5, \beta 6$ y $\beta 7$ plegadas se forman por apareamiento de residuos intercatenarios del extremo $C$-terminal de la proteína. ${ }^{5}$

\section{Receptor}

Se han descrito tres tipos de receptores para que el TGF- $\beta$ lleve a cabo su señalización (TGF- $\beta$ RI de 53 a $65 \mathrm{kDa}, \mathrm{TGF}-\beta \mathrm{RII}$ con 83 a $110 \mathrm{kDa}$ y TGF- $\beta$ RIII que va de 250 a $310 \mathrm{kDa}$ ), aunque algunos investigadores han propuesto que existen dos receptores adicionales que son el tipo IV (TGF- $\beta$ RIV) de $60 \mathrm{kDa}$ y el tipo V (TGF- $\beta \mathrm{RV}$ ) con 400 kDa, identificados sólo en células pituitarias. Se presentan algunas diferencias entre los receptores tipo I y II que se basan en la conservación de los dominios con actividad de cinasa y la presencia de un dominio serina/treonina (dominio GS) que se encuentra anclado a la membrana en el receptor tipo I y el cual es crítico para su activación. Por otro lado, el receptor tipo III, también llamado $\beta$-glicano, no tiene dominio de señalización intracelular y puede ser anclado a la membrana o secretado en forma soluble. ${ }^{6,7,9}$ En mamíferos, sólo cinco receptores tipo II y siete tipo I han sido identificados, y descritos 29 ligandos.

En ausencia de ligando, los receptores tipo I y II existen como homodímeros en la superficie celular.

Los complejos del receptor son heterotetraméricos y consisten de dos receptores tipo II a los cuales se une el ligando, y dos receptores tipo I, que transmiten la señal de transducción, a los cuales, en muchas ocasiones, no puede unirse el ligando directamente. ${ }^{11} \mathrm{El}$ ensamblaje del complejo heteromérico es iniciado por la unión del ligando y estabilizado por las interacciones entre los dominios citoplásmicos de los receptores tipo I y II. Este modelo de activación del receptor involucra la potenciación de la actividad de cinasa del receptor tipo I a través de la fosforilación de dominio GS por el receptor tipo II. ${ }^{5,12}$ Durante la activación del receptor, el T $\beta$ RI actúa después de activado el T $\beta R I I$ en muchos casos, aunque la respuesta mediada por el TGF- $\beta$ y el receptor tipo I determinan la especificidad de señales intracelulares. Una secuencia de nueve aminoácidos entre las sub-unidades IV y V con actividad de cinasa del $\mathrm{T} \beta \mathrm{RI}$ es importante para la transducción de señales específicas del TGF- $\beta$ (figura 2).

Algunos sitios de fosforilación en los receptores $\mathrm{T} \beta \mathrm{RI}$ y T $\beta$ RII se identificaron utilizando receptores quiméricos y silvestres, encontrándose ciertas regiones en el T $\beta$ RII que son importantes en la regulación de la señalización; también la fosforilación de serinas en la posición 213 y 409 son importantes durante la activación del receptor, y la fosforilación de la serina en la posición 416 es indispensable para inhibir la activación del T $\beta$ RII. ${ }^{9,12}$

Existe una afinidad diferencial entre T $\beta$ RI, II y III, sin embargo, no hay relación directa entre la afinidad de unión y el efecto biológico. Los efectos de las isoformas del TGF- $\beta$ están asociados a su disponibilidad, a la combinación de los tipos de receptores y a la vía de señalización intracelular que inducen; por ejemplo, los T $\beta$ RI y II se unen al TGF- $\beta 1$ y al TGF- $\beta 3$ con mayor afinidad que al TGF- $\beta 2 .{ }^{5} \mathrm{El} \beta$-glicano, formalmente llamado receptor tipo III, se puede unir a todas las isoformas del TGF- $\beta$, pero puede jugar un papel selectivo al facilitar la interacción del TGF- $\beta 2$ con el T $\beta$ RII. ${ }^{13,14}$ Todas las células normales y la mayoría de las células neoplásicas tienen receptores en su superficie para el TGF- $\beta 1$. Los receptores I y II son los responsables de los efectos biológicos del TGF $\beta 1$ en las 


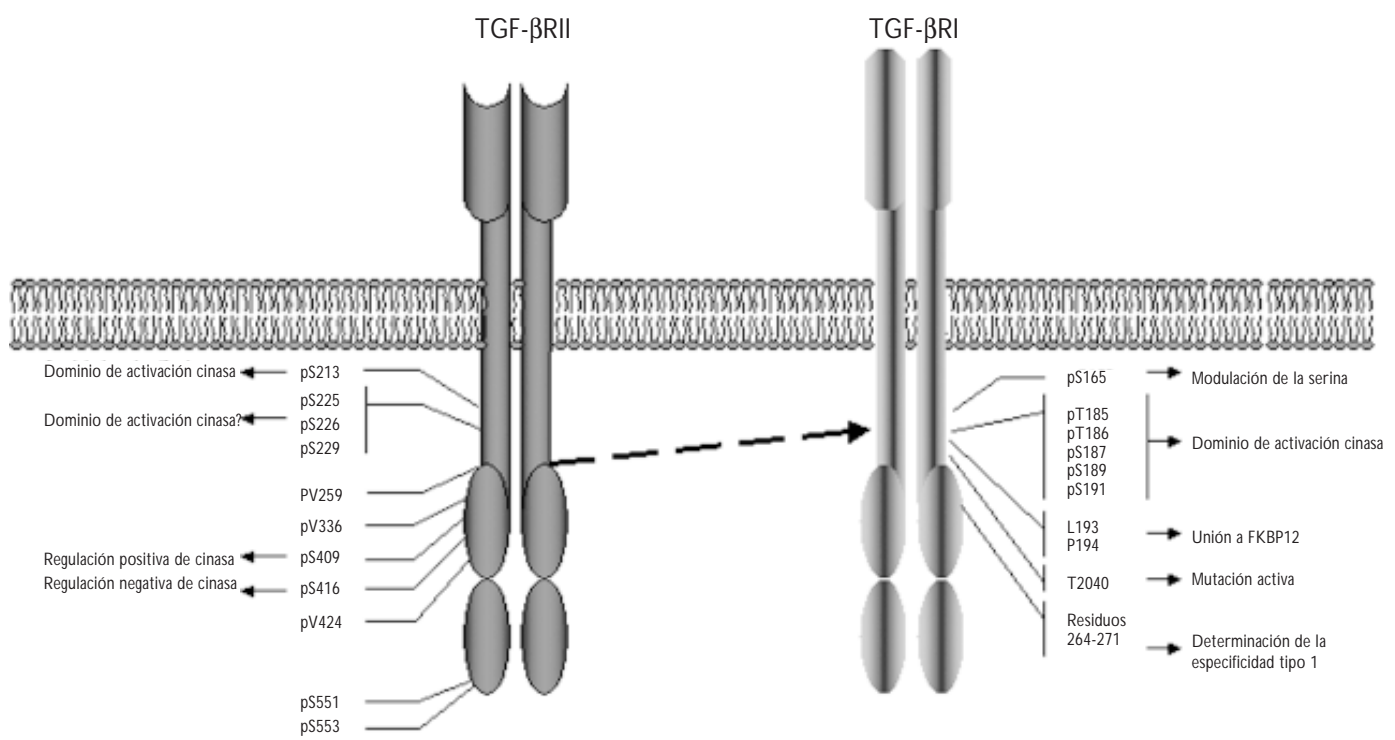

T $\beta$ RI: receptor tipo I de TGF- $\beta$

T $\beta R$ I: receptor tipo II de TGF- $\beta$

pY: sitio de fosforilación de tirosina

pS: sitio de fosforilación de serinas

Figura 2. Sitios de fosforilación durante la activación del T $\beta$ RI y del T $\beta$ RII. El TGF $\beta$ se une en forma DIMÉRICA AL COMPLEJO HETEROTETRAMÉRICO FORMADO POR DOST $\beta$ RII Y DOST $\beta R I$. SE MUESTRAN LOS DOMINIOS GS Y EL DOMINIO CINASA. SITIOS DE AUTOFOSFORILACIÓN EN ELT $\beta R$ RII Y SITIOS FOSFORILADOS EN EL T $\beta R I$ POR ELT $\beta R$ II Y SUS PAPELES FUNCIONALES TAMBIÉN SE INDICAN.TAMBIÉN SE PUEDEN APRECIAR UN RESIDUO DE AMINOÁCIDOS INVOLUCRADO EN LA UNIÓN DE FKBP12, MUTACIONES INVOLUCRADAS EN LA ACTIVACIÓN Y UN SITIO IMPORTANTE EN LA ESPECIFICIDAD DE SEÑALIZACIÓN DELT $\beta R I$

células de mamífero; sin embargo, los receptores tipo III, constituidos por $\beta$-glicanos y endoglina, son también capaces de unirse al TGF- $\beta 1$. Los $\beta$-glicanos están ampliamente distribuidos en células mesenquimales, epiteliales y neuronas; se unen a través de su región extracelular de $100 \mathrm{kDa}$, poseen una región citoplásmica corta y una región intracelular que no participa en la señal de transducción. La endoglina es similar a los $\beta$-glicanos, particularmente en la región citoplásmica, y está presente en altas concentraciones en las células endoteliales. ${ }^{5}$

\section{Las proteínas smad: mediadores de la señal de transducción}

Las proteínas smad han sido identificadas como las principales transductoras de la señalización del TGF- $\beta$, median la señalización del receptor en la superficie celular a los genes blanco en el núcleo. El primer miembro de la familia smad, llamado Mad (mothers against dpp) fue identificado en Drosophila melanogaster; éste fue seguido por la clonación de las proteínas sma 2, sma 3 y sma 4 en Caenorabditis elegans las cuales poseen dominios $\mathrm{C}$-terminal y $\mathrm{N}$-terminal altamente conservados, llamados dominios de homología a Mad 1 y 2 (MH1 y MH2, respectivamente) unidos por una región rica en prolina. ${ }^{12}$ Existen ocho proteínas smad en vertebrados (Smad 1-Smad 8) que han sido descritas con tres distintas funcionalidades: smad activadas por el receptor o R-Smad (Smad 1, 2, 3, 5 y 8), smad mediadora común o C-Smad (Smad4) y, finalmente, las smad inhibitorias o I-Smad (Smad 6 y 7), figura 3.,13-15 A su vez, a las R-Smad se han agrupado en dos grupos principales de acuerdo con la manera como son activadas por su receptor tipo I. Estas incluyen a Smad 2 y Smad 3 que son activadas a través de fosforilación de su segmento $C$-terminal por el receptor tipo I del TGF- $\beta$ y el receptor de activina (T $\beta$ RI y ActRIB, respectivamente); Smad 1, Smad 5 y Smad 8 son activadas por Alk1, Alk2 o BMP. ${ }^{9}$

Estas smad activadas por el receptor son liberadas del complejo del receptor para formar un complejo heterotrimérico de dos R-Smad y una Smad 4, y translocarse dentro del núcleo. ${ }^{3}$ Las R-Smad y Smad 4 con- 


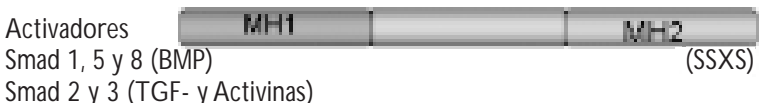

Smad 2 y 3 (TGF- y Activinas)

Mediadores

Smad 4

Inhibidores

Smad 6 y 7

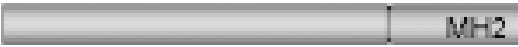

MH 1: dominio 1 de homología mad

MH2: dominio 2 de homología mad

BMP: proteína morfogénica de hueso

SSX S: secuencia rica en serinas

Figura 3. La familia smad. Se MUestran las PRINCIPALES ESTRUCTURAS ESQUEMÁTICAS Y LOS TRES DISTINTOS SUBGRUPOS: R-SMAD, CO-SMAD Y I-SMAD. LA HOMOLOGÍA DE LOS SEGMENTOS MH1 Y MH2 EN LAS REGIONES AMINO Y CARBOXILO TERMINALES, RESPECTIVAMENTE.TAMBIÉN SE MUESTRA EL RESIDUO RICO EN SERINA (SSXS) EN LA REgIÓN CARBOXILO TERMINAL DEL R-SMAD QUE PUEDE SER FOSFORILADO POR EL RECEPTOR TIPO I

tienen un dominio MH1 y MH2 en la región C-terminal que flanquea un segmento medio (de unión). Las I-Smad carecen del dominio MH1 reconocible, pero tienen el dominio MH2. Los dominios MH1 y MH2 pueden interactuar con factores de transcripción de secuencia específicos, donde el C-terminal de las RSmad interactúa y recluta a coactivadores relacionados con la proteína de unión a CREB (CBP) o p300.12,14 Se ha identificado una gran variedad de proteínas, que interactúan con los complejos de receptores, y las RSmad, que son indispensables como chaperonas para el reclutamiento de las smad y su unión a su receptor específico. Entre estos están: el anclaje de las Smad para la activación del receptor (SARA, por sus siglas en inglés), el sustrato tirosinacinasa regulado por el HGF (Hgs, por sus siglas en inglés), Axina, Fodrina de hígado embriónico (ELF, por sus siglas en inglés), la proteína 1 asociada al receptor del TGF $\beta$ (TRAP 1, por sus siglas en inglés), el pseudo gen del polipéptido ligero de ferritina (FTLP, por sus siglas en inglés), y el efector antagonista de la Smad 1 (SANE, por sus siglas en inglés).

\section{Señalización}

En el espacio extracelular, el TGF $-\beta$ se une al T $\beta$ RIII, el cual recluta al T $\beta$ RII y se autofosforila, o el TGF- $\beta$ se puede unir directamente al T $\beta$ RII anclado a membrana e inducir la atracción del T $\beta$ RI y su consecuente fosforilación. Esta fosforilación en el receptor tipo I activa a las cinasas en residuos de tirosina que fosforilan a los factores de transcripción Smad 2 y Smad 3; una vez fosforilados, forman un complejo con Smad 4 para trasladarse del citoplasma hacia el núcleo, donde interactúan de una manera específica con otros factores de transcripción como AP-1, regulando la transcripción de genes de respuesta al TGF- $\beta$ para llevar a cabo sus funciones biológicas de diferenciación, control del crecimiento, apoptosis celular y síntesis de matriz extracelular, entre otras (un ejemplo es el gen de colágena), figura $4.3,9$

Cabe mencionar el papel que juegan ciertas I-Smad, principalmente los tipo Smad-6 y Smad-7, que carecen de la región normalmente fosforilada por el receptor $\mathrm{T} \beta \mathrm{RI}$ y, así, interfieren con la fosforilación de Smad-2 o Smad-3, regulando su actividad. 2,3,9,16

\section{Papel inmunológico}

Algunos estudios enfocados en descubrir el papel del TGF- $\beta$ indican una función en procesos inmunes e inflamatorios, ya que suprime el crecimiento y diferenciación de muchos linajes de células inmunes, incluyendo células T y B. ${ }^{1}$ El TGF- $\beta$ es producido por todas y cada una de las células de linaje inmunológico y actúa de una manera autócrina y parácrina. Además de la regulación de la proliferación de células del sistema de defensa, regula la expresión de moléculas de adhesión, especialmente en la médula ósea y en el microambiente tímico. Este también actúa como un quimioatrayente para fibroblastos, monocitos y neutrófilos e inhibe la activación del sistema inmune por presentación antigénica o de interleucinas (IL). Además, las células T que entran en apoptosis normal son el mayor objetivo del TGF- $\beta$, con una acción inmunosupresora drástica, e in vivo aumenta las funciones efectoras y de memoria de los linfocitos T CD4+ antígeno-específi$\cos$, inhibe la secreción de IgG e IgM, suprime la hematopoyesis dependiente de IL-3. De manera importante y relevante, el TGF- $\beta$ también controla la proliferación y maduración en células $B$ y tiene un papel regulatorio crítico en la expresión de IgA. ${ }^{17}$

\section{TGF $-\beta$ en patologías}

Se sabe que el TGF- $\beta$ tiene un importante papel en la regulación del ciclo celular. En muchas células epiteliales, endoteliales y hematopoyéticas actúa inhibiendo la progresión de la fase G1 del ciclo mitótico, ya que estimula la producción de p15, un inhibidor de 


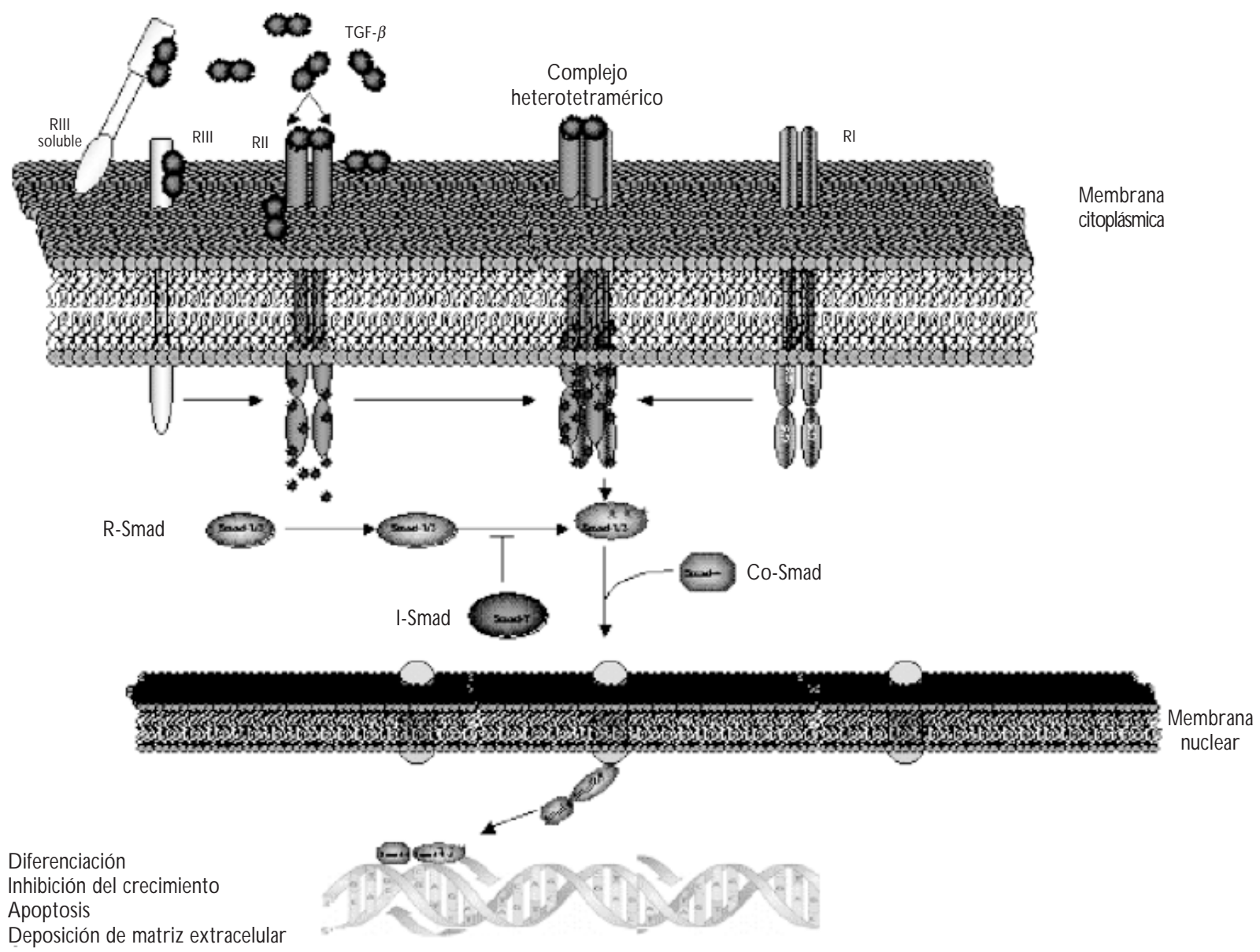

Colágeno tipo I, PAH,TM P-1 c-myc y c-myb

RIII: receptor tipo III de TGF- $\beta$

RIl: receptor tipo II de TGF- $\beta$

RI: receptor tipo I de TGF- $\beta$

GS: secuencia Serina/Treonina

PAI-I: inhibidor tipo I del activador de plasminógeno

TIMP-1 inhibidor tisular tipo I de metaloproteinasa

Figura 4. Mecanismo general de la señalización del TGF- $\beta$. En la superficie Celular, el ligando se une a un COMPLEJO DE RECEPTORES TRANSMEMBRANALES CON ACTIVIDAD DE CINASA EN RESIDUOS DE SERINA/TREONINA (T $\beta$ IR Y T $\beta$ IIR) E INDUCE LA tRANSFOSFORILACIÓN DEL SEGMENTO GS EN EL RECEPTOR TIPO I POR EL RECEPTOR TIPO II. EL RECEPTOR TIPO 1 FOSFORILADO RECLUTA A LAS SMAD RECEPTORAS (SMAD 2 Y 3) QUE SON ACTIVADAS Y FORMAN UN Complejo con SMAd colaborador (SMAd 4), para translocarse al Núcleo y UNIRSE a SECUENCIAS SBE (elemenTOS DE UNIÓN A SMAD) Y ASÍ, LLEVAR A CABO SUS FUNCIONES BIOLÓGICAS.TAMBIÉN SE MUESTRA EL PAPEL QUE JUEGAN LAS SMAd INHIBITORIAs (SMAd 6 y 7) al bloquear La seÑalización eVITANdo qUe SE fosforilen SMAd 2 y 3

cinasas dependientes de ciclinas (CDC). Estos cambios resultan en un decremento en la fosforilación de la proteína $\mathrm{Rb}$, la cual se une y secuestra miembros de la familia de factores de transcripción E2F e inhibe, de esta forma, la expresión de genes que regulan el ciclo celu- lar como los c-myc y c-myb. En las células cancerosas, mutaciones en la vía de señalización del TGF- $\beta$ confieren resistencia a la inhibición del crecimiento $y$, consecuentemente, disparan un crecimiento celular descontrolado. Además de los efectos antes mencio- 
nados, el TGF- $\beta$ también juega un importante papel en la metástasis, ya que induce la expresión, tanto de matriz extracelular como de proteínas de adhesión celular, así como también decrece la producción de enzimas que degradan la matriz, o incrementa los inhibidores de dichas proteínas. Por todo lo anterior, es de suponerse que el TGF- $\beta$ puede incrementar la invasión de las células malignas. Además, el TGF- $\beta$ también induce la formación de nuevos vasos sanguíneos (angiogénesis) y la motilidad celular, y suprime al sistema inmune. La sobreproducción del TGF- $\beta$ puede inducir la acumulación de una cicatriz fibrosa en diferentes órganos (hígado, riñón, pulmón), culminando con un estado patológico muy grave que en muchos casos lleva a la muerte. El TGF- $\beta$ inhibe la proliferación y migración de células endoteliales y de músculo liso. Aunado a todo lo anterior, parece haber una relación entre el grado de expresión del TGF- $\beta$ y la hipertensión arterial, debido a varios factores como elevación en la concentración de angiotensina II, incremento en la presión sanguínea sistémica y polimorfismos en el promotor del TGF- $\beta{ }^{2,18}$

\section{Perspectivas terapéuticas}

El papel del TGF- $\beta$ en varias enfermedades humanas puede darse de dos formas: la primera, involucra un incremento en la actividad, como ocurre en pacientes que cursan con fibrosis, y la segunda, en la que la actividad del TGF- $\beta$ decrece; tal es el caso del cáncer y de la aterosclerosis. Numerosos estudios experimentales encaminados a tratar de modular la expresión de esta fascinante citocina pleiotrópica en diferentes patologías han dado resultados satisfactorios; entre ellos tenemos a la administración de antioxidantes, drogas específicas, extractos de plantas, citocinas antagónicas, supresores de apoptosis, oligonucleótidos antisentido y herramientas de terapia génica con Smad 7, diseñadas específicamente para truncar la señalización del TGF- $\beta$.

Para el caso de fibrosis hepática se han realizado diversos protocolos en los que el punto clave es el TGF- $\beta$. Uno de estos estudios, el de Armendáriz-Borunda y colaboradores, indujo el bloqueo de la producción de esta citocina por las células de Kupffer mediante oligonucleótidos antisentido y el envío de anticuerpos neutralizantes (anti-TGF $\beta$ ) a hígados con daño por $\mathrm{CCl}_{4}$, para monitorear el estado inflamatorio a través de la expresión de citocinas pro-inflamatorias y anti-inflamatorias. ${ }^{19-21}$ Otro acercamiento promisorio es la inhibición de la activación proteolítica del TGF- $\beta$ latente; por ejemplo, el inhibidor de proteasas de serina Camostat que suprime la activación de las células estelares hepáticas al inhibir la actividad de la plasmina, previniendo la fibrosis en el hígado, ${ }^{22}$ y el uso de un péptido sintético que bloquea la unión de trombospondina 1 al péptido asociado a la latencia (LAP) del TGF- $\beta$ latente en un modelo de fibrosis hepática; de igual manera, se inhibió la activación de las células estelares hepáticas mediante un protocolo de terapia génica con Smad 7.10,23

Recientemente, nuestro grupo ha realizado experimentos para bloquear la señalización del TGF- $\beta$ mediante la expresión local de un receptor dominante negativo tipo II, que carece del dominio intracitoplasmático serina/treonina $(\Delta \mathrm{CyT} \beta \mathrm{RII})$ en fibrosis hepática experimental, tanto in vivo como in vitro, al disminuir la expresión de colágena y alterar la actividad de las Smad 2 y 3, concluyendo que esta tecnología podría ser útil para disminuir o prevenir la síntesis exacerbada de matriz extracelular en procesos fibróticos; ${ }^{2,8,24}$ o la utilización del receptor soluble del TGF- $\beta$ que secuestra a su ligando TGF- $\beta$, e impide que éste llegue a su receptor. ${ }^{25}$ Similarmente, se ha observado que la fibrosis inducida por ligadura del ducto biliar fue suprimida en una alta proporción por la expresión de una proteína de fusión del dominio Fc- de la inmunoglobulina $\mathrm{G}$ y la porción extracelular del receptor truncado del TGF- $\beta$, actuando como un barredor de esta citocina. . $^{26,27}$

Debido a sus efectos celulares, el TGF- $\beta$ es capaz de regular los eventos patofisiológicos in vivo, como el desarrollo embrionario normal, la angiogénesis en tejido tumoral, la transformación maligna y la vigilancia inmune. Como papel general, el efecto directo del TGF- $\beta$ en las células cancerosas es la inhibición del crecimiento del cáncer. Las células cancerosas son capaces de adquirir la habilidad de evadir el efecto inhibitorio del TGF- $\beta$. Estas células malignas son capaces de producir grandes cantidades del TGF- $\beta$ y esta cantidad excesiva promueve la angiogénesis tumoral y la supresión inmune..$^{28}$

La evidencia de que el TGF- $\beta$ suprime la progresión del tumor lo hace un blanco atractivo para la intervención terapéutica; a este respecto, pequeñas moléculas inhibitorias como SB431542 disminuyen la actividad cinasa del T $\beta$ RI, y algunos agentes que bloquean la señalización del TGF- $\beta$ se encuentran en diferentes protocolos clínicos y pre-clínicos. Se ha utilizado de manera experimental una proteína de fusión soluble que comprende la región Fc- de la inmunoglobulina humana y T $\beta$ RII (Fc-T $\beta$ RII) que antagoniza la señalización del TGF- $\beta$ e inhibe la metástasis de tumor mamario a pulmón, cuando es utilizada como una droga inyectable o cuando es expresada como transgen en glándula mamaria. La exposición crónica al 
Fc-T $\beta$ RII no causa fenotipo autoinmune ni inflamatorio en ratones transgénicos, ni estos animales desarrollan tumores espontáneos. ${ }^{29}$ También se ha comprobado que el inhibidor de fosfatidilcolina de fosfolipasa C (PC-PLC), conocido como D609, bloquea la señalización del TGF- $\beta$ en células de carcinoma pulmonar A549. ${ }^{30} \mathrm{Se}$ ha reportado un efecto inhibitorio de Smad 4 en la angiogénesis e invasión de tumores pancreáticos. La transferencia adenoviral de este gen en una línea de células de tumores pancreáticos deletados de Smad 4 de manera homocigótica restauró la expresión de la proteína y su función, aunque esto no afectó la proliferación in vitro, Smad 4 inhibió in vivo el crecimiento tumoral en ratones inmunodeficientes, al disminuir la expresión del factor de crecimiento del endotelio vascular (VEGF, por sus siglas en inglés) y de gelatinasas, reportándose con ello una reducida invasión, angiogénesis y una regulación negativa recíproca entre Smad 4 y ETS-1 (marcador de invasión tumoral). ${ }^{31}$

Múltiples estudios en animales y humanos sostienen un papel directo del TGF- $\beta$ en procesos fibrogénicos in vivo. Hay evidencias de que la concentración del TGF- $\beta 1$ está bajo control genético, lo que implica que la variación genética del locus del TGF- $\beta 1$ puede influir en las enfermedades, incluyendo la fibrosis pulmonar idiopática. Xaubet y colaboradores han descubierto polimorfismos en el gen del TGF- $\beta 1$ en 128 pacientes con fibrosis pulmonar. Ellos estudiaron dos polimorfismos en el exon 1, en las posiciones +869 y +915 , que ocasionan una sustitución de una leucina a prolina en el codón 10, y de arginina a prolina en el codón 25. El polimorfismo en el codón 10 se asocia con un deterioro en la función pulmonar, con un significativo incremento en la tensión de oxígeno alveolar-arterial. Por tanto, Xaubet propone el uso de marcadores genéticos que permitan la identificación de pacientes más propensos a la enfermedad, que podrían ser más fácilmente detectados para un tratamiento anti-

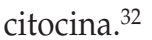

Algunos investigadores han demostrado en diversos trabajos que la fibrosis pulmonar puede ser inducida experimentalmente por la sobrexpresión del TGF- $\beta 1$ o mediante el envío de adenovirus que portan el cDNA del TGF- $\beta$ instilados en pulmón, con el objetivo de establecer un modelo que ayude a entender algunos aspectos cuantitativos de la actividad biológica del TGF- $\beta 1$ y tratar de manipular este potente factor como un mediador de fibrogénesis intersticial. 33,34 Por otro lado, la terapia génica con la smad inhibitoria (Smad 7) bloquea la cascada de señalización e inhibe la fibrosis pulmonar experimental inducida por bleomicina; ${ }^{35}$ de manera similar, la administración de vectores adenovirales recombinantes, que llevan inserto el cDNA del receptor tipo II del TGF- $\beta$ soluble, reduce la disponibilidad del TGF- $\beta 1$ activo y protege al pulmón del daño inducido por radiación en ratas. ${ }^{36}$

La histología del riñón es alterada dramáticamente en todos los pacientes diabéticos. Los cambios estructurales tempranos consisten en hipertrofia glomerular y tubuloepitelial. En estos pacientes, destinados a desarrollar insuficiencia renal, las proteínas de matriz extracelular se acumulan en el mesangio, obliterando los capilares glomerulares que lo rodean y reduciendo la capacidad de filtración glomerular. De una manera similar, la matriz extracelular se acumula en el intersticio tubular y alrededor de las arteriolas, conduciendo a la destrucción de las nefronas. Todos estos factores conducen a una enfermedad denominada nefropatía diabética y, en la última década, se han realizado investigaciones sobre una molécula efectora clave, responsable de la estimulación de las células renales para entrar en hipertrofia y a sobrexpresar proteínas de matriz extracelular; estos cambios son provocados por el TGF- $\beta$, una citocina hipertrófica y proesclerótica que afecta las celulas glomerulares, tubulares y los fibroblastos intersticiales. El TGF- $\beta$ ha demostrado mediar virtualmente todos los cambios patológicos en enfermedades del riñón diabético. ${ }^{37}$ De manera experimental se han utilizado oligonucleótidos antisentido contra una proteína de matriz extracelular homotrimérica (trombospondina 1), que participa en la activación no proteolítica del TGF- $\beta$ latente, para que éste pueda unirse a su receptor y continúe con sus efectos biológicos. ${ }^{38}$

Otra perspectiva terapéutica es la realizada por Zhu y colaboradores, en la que demuestran que el envío adenoviral del gen del dominio extracelular soluble del receptor tipo II del TGF- $\beta$ (T $\beta$ RII), fusionado a la porción Fc de la inmunoglobulina G humana y expresado en el sistema músculo-esquelético disminuye la disfunción renal y la cicatriz fibrosa en un modelo de nefritis de membrana basal antiglomerular (GBM, por sus siglas en inglés). ${ }^{3}$ La fibrosis tubulointersticial es el resultado final de una variedad de daños progresivos que conducen a la falla renal crónica. Como el TGF- $\beta$ se sobrexpresa en respuesta a estímulos perjudiciales en riñón, como la obstrucción ureteral unilateral, causando fibrosis asociada con la transición epitelial-mesenquimal de los túbulos renales y la síntesis de matriz extracelular, los trabajos de Sato y colaboradores demuestran que la carencia de Smad 3, una intermediaria clave en la señalización del receptor del TGF $-\beta$, protege al riñón de la fibrosis tubulointersticial, como se evidencia por el bloqueo de la transición epitelial-mesenquimal y de acumulación de colágena. Estos datos demuestran que la vía de Smad 3 es cen- 
tral en la patogénesis de la fibrosis intersticial y sugiere que los inhibidores de esta vía podrían tener aplicación clínica en el tratamiento de nefropatías obstructivas. $^{39}$

La ateroesclerosis es una enfermedad inflamatoria de la pared arterial, en la cual el papel que desempeñan ciertos mediadores proinflamatorios está bien fundamentado. El entendimiento de la actividad de los componentes antinflamatorios que participan en la modulación de la progresión de la placa ateroesclerótica se encuentra en etapas iniciales. Como los TGF- $\beta 1, \beta 2$ y $\beta 3$ son factores de crecimiento con gran actividad en células y tejidos en el sistema cardiovascular, se ha propuesto una participación en la patogénesis de la ateroesclerosis; esto ha dado inicio a estudios científicos, como los de Mallat y colaboradores, quienes demostraron que la inhibición de la señalización del TGF- $\beta$ utilizando un anticuerpo neutralizante contra los TGF- $\beta 1, \beta 2$ y $\beta 3$, que impide la unión del TGF- $\beta$ a su receptor, acelera el desarrollo de la placa ateroesclerótica en ratones deficientes de apolipoproteína E (apoE). Además, la inhibición de la señalización favorece el desarrollo de la lesión con un incremento en los componentes inflamatorios y un decremento en el contenido de colágena. De esta manera, se demuestra el efecto protector de TGF $-\beta$ en la ateroesclerosis. ${ }^{40}$

Otros estudios ponen de manifiesto la importancia que tiene el TGF- $\beta$ como una citocina inmunomoduladora que regula la activación de las células $\mathrm{T}$ para detener la ateroesclerosis, como lo demostraron Robertson y colaboradores, al truncar la señalización del TGF- $\beta$, en ratones deficientes de apoE, cruzados con ratones transgénicos que portaban el receptor tipo II dominante negativo en sus células T, lo cual dió como resultado un incremento en la ateroesclerosis, expresión de interferón a (IFN-a), una reducida placa de colágena, incrementada activación de células $\mathrm{T}$ y secreción de citocinas. ${ }^{41}$

\section{Conclusiones}

El TGF- $\beta$ es una familia de alrededor de 35 proteínas, descubiertas durante los años 70 y 80, que están ampliamente distribuidas de manera temporoespacial en los organismos metazoarios. De ellas, el TGF- $\beta$, propiamente dicho, es una molécula sintetizada como un precursor inactivo que puede convertirse en una forma funcional por múltiples mecanismos, entre ellos están un $\mathrm{pH}$ extremo, altas temperaturas, proteolisis limitada o desglucosilación del péptido asociado a la latencia, sin olvidar el mecanismo realizado por la trombospondina 1. Debido a que es una molécula cla- ve, tanto durante el desarrollo embrionario como en el adulto, al actuar de diferente manera (proliferación, migración, inmunomodulación y apoptosis, entre otras) en cada uno de los diferentes tipos celulares, así como durante condiciones patofisiológicas que involucran una gran variedad de órganos como hígado, pulmón, riñón y sistema vascular, el TGF- $\beta$ se vale de tres tipos principales de receptores (T $\beta$ RI, T $\beta$ RII y $\mathrm{T} \beta$ RIII) con actividad de cinasa en la región intracitoplásmica, $\mathrm{y}$, con ayuda de unos segundos mensajeros llamados smad, para que se lleve a cabo la señalización desde el exterior de la célula hacia el núcleo, de donde proceden sus funciones biológicas. No debe olvidarse que esta fascinante citocina también regula procesos inmunes muy importantes para el correcto funcionamiento del sistema, por ejemplo, regular la proliferación de los linajes celulares $\mathrm{T}$ y B, así como también la expresión de algunas inmunoglobulinas como la IgA, la IgM e IgG. Ante algunos daños fisiológicos, la actividad del TGF- $\beta$ se ve alterada, en muchos casos induciendo una sobrexpresión de la misma, provocando alteraciones en los órganos, al mismo tiempo que aparecen diversos padecimientos que en muchas ocasiones culminan con la muerte del paciente, como insuficiencia renal crónica, cirrosis hepática, fibrosis pulmonar y cáncer. Debido al considerable avance científico que se tiene para entender la bioquímica básica de la vasta cantidad de moléculas involucradas en la señalización del TGF- $\beta$, el gran número de ligandos que posee, la plasticidad de los receptores y la incrementada cantidad de información científica que se posee sobre la participación de esta molécula en patologías humanas, se están desarrollando novedosos protocolos experimentales de investigación, enfocados en corregir la alteración presente en la ruta de actividad del TGF- $\beta$, la que puede ir desde la expresión del RNA, y la síntesis proteica hasta cada uno de los eventos moleculares que intervienen de manera importante en la señalización de esta "versátil" molécula.

\section{Referencias}

1. Sporn M.TGF- $\beta: 20$ years and counting. Microbes Infect 1999;1: 1251-1253.

2. Blobe $G$, Schiemman W, Lodish H. Role of transforming growth factor B in human disease. N Engl J Med 2000;4:1350-1358.

3. Zhu H, Burgess A. Regulation of transforming growth factor $B$ signaling. Mol Cell Biol Res Community 2001;4:321-330.

4. Miyazono K. Positive and negative regulation of TGF $\beta$ signaling. J C ell Sci 2000;113:1101-1109.

5. Peralta-Zaragoza 0, Lagunas-Martínez A, Madrid-MarinaV.

Transforming growth factor beta-1: Structure, function, and regulation mechanisms in cancer. Salud Publica Mex 2001;43:340-351. 
6. Border W, N oble N .TGF- $\beta$. Sci Am Sci Med 1995;2:68-77. 7. Bissell $M$, Roulot $D, G$ eorge J.Transforming growth factor and the liver. Hepatology 2001;34:859-867.

8. Hernández-C añaveral I, González J, López-C asillas F,ArmendárizBorunda J.A mplified expression of dominant-negative transforming growth factor-beta type II receptor inhibits collagen type I production via reduced Smad-3 activity. J Gastroenterol Hepatol 2004;19:380-387. 9. Caestecker $M$. The transforming growth factor-B superfamily of receptors. Cytokine Growth Factor Rev 2004;15:1-11.

10. Kondou H, Mushiake S, Etani Y, Moyoshi Y, Michigami T, 0 zono K.A blocking peptide for transforming growth factor-B1 activation prevents hepatic fibrosis in vivo. J Hepatol 2003;39:742-748.

11. Susumu I, Fumiko I, G oumans M, D ijke T. Signaling of transforming growth factor-B family members through Smad proteins. Eur J Biochem 2000;267:6954-6967.

12. Heldin CH, Miyazono J, Dijke P.TG F- $\beta$ signaling from cell membrane to nucleus through SMAD proteins. N ature 1997;390:465-471.

13. Roberts A.TG F- $\beta$ signaling from receptors to the nucleus. Microbes Infect 1999;1:1265-1273.

14. D erynck $R$, Zhang Y. Smad-dependent and smad-independent pathways in TG F- $\beta$ family signaling. $N$ ature 2003:425:577-584.

15. W hitman M. Feedback from inhibitory SMADs. $N$ ature 1997;389:549-551.

16. Dijke Pt, Miyazono K, CH H. Signalling inputs converge on nuclear effectors in TG F- $\beta$ signaling. Trends Biochem Sci 2000;25:64-70. 17. Moustakas A, Pardali K, G aal A, Heldin CH. Mechanism of TGF- $\beta$ signaling in regulation of cell growth and differentiation. Immunol Lett 2002;82:85-91

18. Lijnen P, PetrovV, Fagard R.Association between transforming growth factor-B and hypertension. Am J Hypertens 2003;16:604-611. 19.Armendáriz-Borunda J, LeG ros L, C ampollo 0, Panduro A, Rincón A. Antisense S-oligodeoxynucleotides down-regulate TG FB-production by Kupffer cells from CCL4-injured rat livers. Biochim Biophys Acta 1997;1353:241-252.

20. D elgado-Rizo V, Salazar A, Panduro A,Armendáriz-Borunda J. Treatment with anti-tumor growth factor $B$ antibodies influences an altered pattern of cytokines gene expression in injured rat liver. Biochim Biophys Acta 1998; vol 1442(1):20-27.

21. Gressner A,W eiskirchen R, Breitkopf $K$, D o oley S. Roles of TGF- $\beta$ in hepatic fibrosis. Front Biosci 2002;7:793-807.

22. 0 kuno M,Akita K, Moriwaki H, Kawada N, Ikeda K, Kaneda K et al. Prevention of rat hepatic fibrosis by the protease inhibitor, camostat mesilate, via reduced generation of active TG F- $\beta$. G astroenterology 2001;120:1781-1800.

23. D o oley S, Hamzavi J, Breitkopf K,W iercinska E, Said H, Lorenzen J et al. Smad-7 prevents activation of hepatic stellate cells and liver fibrosis in rats. Gastroenterology 2003;125:178-191.

24. A rias M, Sauer-Lehnen S, Treptau J, Janoschek N, Theuerkauf I, Buettner $\mathrm{R}$ et al.Adenoviral expression of a transforming growth factor $B 1$ antisense $m R N A$ is effective in preventing liver fibrosis in bile-duct ligated rats. BMC Gastroenterology 2003;3:1-12.

25. YataY, G otwals P, Koteiansky V, Rockey D. D ose-dependent inhibition of hepatic fibrosis in mice by aTGF- $\beta$ soluble receptor: Implications for antifibrotic therapy. Hepatology 2002;35:1022-1030.
26. George J, Roulot D, Koteliansky V,Vissell D. In vivo inhibition of rat stellate cell activation by soluble transforming growth factor beta type II receptor:A potential new therapy for hepatic fibrosis. Proc $\mathrm{N}$ atl Acad Scil USA 1999:96:12719-12724.

27. Isaka Y, A kagi Y,Ando Y, T sujie M, Sudo T, 0 hno N et al. Gene therapy by transforming growth factor-beta receptor-lgG Fc chimera suppressed extracellular matrix accumulation in experimental glomerulonephritis. Kidney Int 1999;55:465-475.

28. Huang X, Lee C. From TGF- $\beta$ to cancer therapy. Curr D rug Targets 2003:4:243-250.

29. Siegel P, Massague J. Cytostatic and apoptotic actions of TG F- $\beta$ in homeostasis and cancer. Nature Rev Cancer 2003;3:807-817. 30. Ignotz R, H oneyman T.TG F- $\beta$ signaling in A 549 lung carcinoma cells: Lipid second messengers. J Cell Biochem 2000;78:588-594.

31. D uda D, Sunamura M, Lefter L, Furukawa T,YokoyamaT,Yatsuoka T et al. Restoration of Smad4 by gene therapy reverses the invasive phenotype in pancreatic adenocarcinoma cells. 0 ncogene 2003;22:6857-6864.

32. Moira K. Genetic factors in idiopathic pulmonary fibrosis: Transforming growth factor- $B$ implicated at last. Am J Respir C rit Care Med 2003;168:410-411.

33. W arshamana GD P, Fisher K, Liu J, Sime P, Brody A. Titration of nonreplicating adenovirus as a vector for transducing active TG F- $\beta 1$ gene expression causing inflammation and fibrigenesis in the lungs of $\mathrm{C} 57 \mathrm{BL} /$ 6 mice. Int J Exp Pathol 2002;83:183-201.

34. Kenyon N , W ard R, McGrew G, Last J.TGF- $\beta 1$ causes airway fibrosis and increased collagen I and III mRN A in mice.Thorax 2003;58:772-777. 35. N akao A, Fujii M, Matsumura R, Kumano K, Saito Y, Mlyazono K et al. Transient gene transfer and expression of Smad 7 prevents bleomycininduced lung fibrosis in mice.J Clin Invest 1999;104:5-11. 36. Rabbani Z,A nscher M, Z hang X, C hen L, Samulski T, Li C et al. Soluble TG F- $\beta$ type II receptor gene therapy ameliorates acute radiation-induced pulmonary injury in rats. Int I Radiat 0 ncol Biol Phys 2003:57:563-572.

37. Chen S, Jim B, Ziyadeh F. D iabetic nephropathy and transforming growth factor B:Transforming our view of glomerulosclerosis and fibrosis build-up. Sem N ephrol 2003;23:532-543.

38. D aniel C, Takabatake Y, Mizui M, IsakaY, Kawashi H, Ruppecht $\mathrm{H}$ et al. Antisense oligonucleotides against thrombospondin- 1 inhibit activation of TG F- $\beta$ fibrotic renal disease in the rat in vivo.Am J Pathol 2003;163:1185-1192.

39. Sato M, Muragaki Y, Saika S, Roberts A, 0 oshima A. Targeted disruption of TG F-beta1/Smad3 signaling protects against renal tubulointerstitial fibrosis induced by unilateral ureteral obstruction. J Clin Invest 2003;112:1486-1494.

40. Mallat Z, Gojova A, Marchiol-Fournigault C, Esposio B, Kamaté C, Merval $R$ et al. Inhibiton of transforming growth factor $B$ signaling accelerates atherosclerosis and induces an unstable plaque phenotype in mice. Circ Res 2001;89:930-934

41. Robertson A, Rudling M, Z hu X, Gorelik L, Flavell R, Hansson G. Disruption of TG F- $\beta$ signaling in T cells accelerates atherosclerosis. J Clin Invest 2003;112:1342-1350. 